\title{
LA PUGNA ENTRE MILITARES Y CIVILES POR EL CONTROL DE LA ACTIVIDAD INTERVENTORA EN EL PROTECTORADO ESPAÑOL EN MARRUECOS (1912-1956)
}

\author{
por \\ JOSE LUIS VILLANOVA \\ Universidad de Girona
}

RESUMEN: La intervención de la actuación de las autoridades marroquíes por parte de las españolas constituyó el principio rector de la administración del Protectorado español en Marruecos (1912-1956). Sin embargo, la falta de una politica colonial definida, el rechazo de gran parte de la población de la Zona española a aceptar el Protectorado y los planteamientos de numerosos militares provocaron que, hasta la total dominación de la Zona en 1927, predominara la administración directa en el ámbito rural frente a una auténtica política de intervención.

Por otra parte, el carácter predominantemente militar que presentó la Administración española en la Zona provocó que la actividad interventora fuera ejercida mayoritariamente por oficiales del Ejército o por elementos provenientes del mismo, en detrimento del personal civil; que siempre fue considerado, en los ambientes castrenses, poco apto para desarrollar la intervención.

Palabras Clave: Protectorado español en Marruecos. Administración directa. Administración indirecta. Intervención civil. Intervención militar.

ABSTRACT: The "contrôle» of the Moroccan authorities was the guiding principle of the Spanish Protectorate administration in Morocco (1912-1956). However, direct rule was the norm in rural areas before the completion of total control of the Zone in 1927, due to several factors: the lack of a well-defined colonial policy, the refusal of the majority of the population in the Spanish Zone to accept the Protectorate and the activity of parts of the army. On the other hand, since the Spanish Administration in the Zone was essentially conducted by the army, the "contrôle" of Moroccan authorities was exercised by military officers and not by civil servants. This latter were considered in military circles as not adequate for the "contrôle» function.

Hispania, LXV/2, núm. 220 (2005) 683-716 
KEY WORDS: Spanish Protectorate in Morocco. Direct rule. Indirect rule. Civil «contrôle». Military «contrôle».

\section{INTRODUCCIÓN}

Los estudios sobre el Protectorado de España en Marruecos (1912-1956) han experimentado, los últimos años, un impulso notable; sin embargo, numerosos aspectos de la presencia colonial española en este país del Magreb todavía no han despertado apenas el interés de los investigadores.

Entre las lagunas existentes, llama la atención la escasez de aportaciones específicas sobre los interventores ${ }^{1}$ : los auténticos puntales de la acción colonial española durante el Protectorado ${ }^{2}$.

La función interventora en el Protectorado español en Marruecos tuvo su origen legal en el convenio franco-español de 27-11-1912 que determinó el carácter de la influencia española en la Zona ${ }^{3}$. En su artículo $1^{\circ}$ estableció que correspondía a España

\footnotetext{
1 Algunos especialistas ya han mencionado este vacío. Véanse, por ejemplo: MORALES LEZCANO, Víctor: España y el Norte de África: el Protectorado en Marruecos (1912-1956), Madrid, Universidad Nacional de Educación a Distancia, 1986, $2^{\text {a }}$ ed., p. 120 y HART, David M.: «Preámbulos y estudios introductorios» en MOGa Romero, Vicente y Bravo NiETO, Antonio (eds.): Emilio Blanco Izaga. Coronel en el Rif. Una selección de su obra, publicada e inédita, sobre la estructura sociopolítica de los rifeños del Norte de Marruecos, Melilla, Ayuntamiento de Melilla \& Universidad Nacional de Educación a Distancia - Centro Asociado de Melilla, 1995, pp. 17-108/47.

${ }^{2}$ Entre los pocos trabajos existentes merecen citarse: TORRES ESCOBAR, Francisco: «La Intervención en el Protectorado de Marruecos (1936-1956)" en Revista de la Universidad Complutense (Madrid) 116 (1980), pp. 465-486; TEIJEIRO DE LA RosA, Juan Miguel: «El Servicio de intervenciones en Marruecos «, Actas del Congreso Internacional: El Estrecho de Gibraltar, Ceuta, Noviembre 1987, Madrid, Universidad Nacional de educación a Distancia \& Ayuntamiento de Ceuta, 1988, vol. 3, pp. 455-466; MOGA ROMERO, Vicente: «Etnografía e intervención militar en el Rif durante el protectorado español de Marruecos» en Fundamentos de Antropología (Granada) 4-5 (1996), pp. 253-255 $\mathrm{y}$ «Estudio introductorio. La celebración del misterio rifeño. Emilio Blanco de Izaga en Beni Aammart (1930)» en BLANCO DE IZAGA, Emilio: La vivienda rifeña. Ensayo de característica e interpretación con ilustraciones del autor (1930), Melilla, Ciudades Autónomas de Ceuta y Melilla. Consejerías de Cultura, 2000, $2^{\mathrm{a}}$ ed., pp. 17-102; MATEO DIESTE, Josep Lluís: El «moro» entre los primitivos. El caso del Protectorado Español en Marruecos, Barcelona, Fundación «La Caixa», 1997, pp. 89-106, «Los interventores militares del Protectorado Español de Marruecos» en Cuadernos del Archivo municipal de Ceuta (Ceuta) 11 (1997), pp. 96-106 y La «bermandad» bispano-marroquí. Política y religión bajo el Protectorado español en Marruecos (1912-1956), Barcelona, Bellaterra, 507 p.; y VILlANOVA, José Luis: La organización política, administrativa y territorial del Protectorado de España en Marruecos (19121956). El papel de la Intervenciones, Tesis Doctoral inédita, Girona, Departament de Geografia, Història i Història de l'Art. Universitat de Girona, 2003, vol. 2, 419 p.

3 Conviene aclarar, para evitar confusiones, que no nos referimos a la Intervención Especial en la Zona creada por Real Decreto 18-10-1913 y dependiente del Ministerio de Hacienda, que controlaba fiscalmente la gestión de la parte de los Presupuestos españoles anuales destinada a la acción española en Marruecos. Véase RAQUEJO Alonso, Antonio: «La Intervención General de la Admi-
}

Hispania, LXV/2, núm. 220 (2005) 683-716 
«velar por la tranquilidad en dicha zona y prestar su asistencia al Gobierno marroquí para la introducción de todas las reformas administrativas, económicas, financieras, judiciales y militares de que necesita $[\ldots .$.$] Las regiones comprendidas$ en la Zona de influencia [...] serán administradas, con la intervención de un Alto Comisario español, por un Jalifa que el Sultán escogerá de una lista de dos candidatos presentados por el Gobierno español [...] Los actos de la Autoridad marroquí en la zona de influencia española serán intervenidos por el Alto Comisario y sus Agentes»4.

Así pues, la intervención consistía básicamente en la «fiscalización del uso que de su autoridad hacen las jerarquías indígenas"s; pero al mismo tiempo, y conforme a los principios del régimen de protectorado, debía incluir la «educación» de las autoridades marroquíes para que ejercieran sus atribuciones. Por otra parte, al ser los interventores los representantes de la Administración colonial en las cabilas - tribus-, también asumieron progresivamente otras muchas atribuciones: proporcionar a la superioridad todo tipo de informaciones sobre el territorio y la sociedad de la Zona española, elevar propuestas acerca de la organización del Protectorado en múltiples facetas (delimitación de las circunscripciones administrativas, desarrollo económico, sanitario y educativo, infraestructuras, etc.), colaborar con los servicios técnicos e incluso realizar aquellas obras que estuvieran a su alcance ${ }^{6}$.

A la vista del citado convenio puede establecerse la importancia de la función interventora: la actuación de las autoridades marroquíes - teóricas detentadoras del poder la Zona- sería fiscalizada por las autoridades protectoras y, a través de dicha inspección, España podría desarrollar su política colonial. Por esta razón, diversos autores de la época subrayaron la significación de la intervención: el secretario general Luciano López Ferrer apuntó que el «elemento esencial» de la acción española era la "constante intervención cerca de las autoridades indígenas»; el capitán Carlos Muñoz Rocatallada la consideró «la función más importante, la más necesaria y la verdadera espina dorsal de toda or-

nistración del Estado, 1808-1974» en LADERO QUESADA, Miguel Ángel et alii.: Itinerario Histórico de la Intervención General de la Administración del Estado, Madrid, Ministerio de Hacienda, 1976, pp.193-697/351-358. Esta Intervención Especial fue reorganizada por el Decreto 26-2-1935 bajo el nombre de Servicios de Intervención económico-legal del Protectorado y puesta bajo dependencia de la Presidencia del Gobierno. Durante la Guerra Civil, la Ordenanza de Alto Comisario 28-121936 los adscribió a la Delegación de Hacienda de la Alta Comisaría. Esta intervención no afectaba en nada a la gestión de las autoridades marroquíes, actividad reservada a la Intervención a la que nos referimos en este artículo.

${ }^{4} \mathrm{El}$ texto del convenio puede consultarse en MORA Regil, E. y RODRígueZ AgUiLerA, C.: Leyes de Marruecos, Madrid, Instituto Editorial Reus, 1947, pp. 15-24.

s CORDERo TORReS, José María: Organización del Protectorado español en Marruecos, vol. 2, Madrid, Editora Nacional, 1942-1943, p. 5.

6 Véase VILlaNOVA, José Luis: La organización política, administrativa y territorial del Protectorado de España en Marruecos (1912-1956). El papel de la Intervenciones, op. cit., vol. 2, pp. 445-480.

Hispania, LXV/2, núm. 220 (2005) 683-716 
ganización de Protectorado»; José María Cordero Torres precisó que «la clave del Protectorado marroquí se encuentra en la gestión desarrollada por el sistema de Intervenciones» y que la intervención constituía «la médula de la gestión de protectorado» y el teniente coronel Ángel Doménech Lafuente - secretario general del África Occidental Española - la calificó de «clave de bóveda del edificio marroquí» ${ }^{7}$. También autores contemporáneos han insistido en esta idea y la han considerado un «vital instrumento del colonialismo» o «más que ninguna otra cosa, la piedra angular de la administración española» ${ }^{8}$.

La implantación del régimen de protectorado comportaba la obligación de respetar las instituciones, leyes, usos y costumbres de Marruecos, por lo que la acción protectora debía ejercerse a través de las autoridades marroquíes: vigilando su actuación, aconsejándolas y, si era necesario, corrigiéndolas. España tenía que impulsar las instituciones propiamente marroquíes, adaptándolas al nuevo sistema que deseaba implantar. El convenio hispano-francés de 1912 no especificó la forma cómo debía ejercerse la acción protectora y las autoridades españolas debieron afrontar no pocas dificultades para concretarla. En primer lugar, España carecía de experiencia en la administración de territorios coloniales establecidos bajo la fórmula de protectorado, como era el caso de Francia. En segundo, tampoco existía en la Metrópoli una idea clara sobre cómo orientar la política colonial. En tercer lugar, la mayor parte de la Zona escapaba al control directo de las autoridades majzenianas y sus habitantes no reconocían la validez del convenio, por lo que rechazaban la fórmula instaurada. Por último, los cambios de gobierno y de régimen que se sucedieron en España provocaron numerosos vaivenes en la política colonial, en general, y en el desarrollo de la intervención, en particular.

\section{INTERVENCIÓN VERSUS GOBIERNO DIRECTO}

El sistema de protectorado se fundamentaba en el principio de la intervención de las autoridades marroquíes por las españolas, a diferencia del sistema colonial en el que las autoridades metropolitanas ejercían el gobierno directo.

\footnotetext{
7 Véanse, respectivamente: LÓPEZ FERRER, Luciano: Naturaleza jurídica del protectorado español en Marruecos, Madrid, Publicaciones de la Real Academia de Jurisprudencia y Legislación, 1923, p. 33; MUÑOz RoCATALlada, Carlos: «Intervenciones Indígenasi en Revista de Tropas Coloniales (Ceuta) 1 (1924), pp. 24-25/ 24; CORDERO TORRES, José María: Organización del Protectorado español en Marruecos, op. cit., pp. 5-6 y DOMÉNECH LAFUENTE, Ángel: Apuntes sobre geografía de la zona norte del protectorado de España en Marruecos, Ceuta, Imprenta Imperio, 1940, 2a ed., p. 63.

${ }^{8}$ Respectivamente, MORALES LezCANO, Víctor: España y el Norte de África: el Protectorado en Marruecos (1912-1956), op. cit., p. 120 y HART, David M.: «Preámbulos y estudios introductorios» en Moga Romero, Vicente y Bravo Nieto, Antonio (eds.): Emilio Blanco Izaga. Coronel en el Rif. Una selección de su obra, publicada e inédita, sobre la estructura sociopolítica de los rifeños del Norte de Marruecos, op. cit., p. 41.
}

Hispania, LXV/2, núm. 220 (2005) 683-716 
El mariscal Hubert Lyautey - primer résident général del Protectorado francés en Marruecos - sintetizó la concepción del protectorado en una circular de 1920:

«es la de un país que conserva sus instituciones, gobernándose y administrándose él mismo con sus propios órganos, bajo el simple control de una potencia europea, la cual, le sustituye en su representación exterior, toma generalmente la administración de su ejército, de sus finanzas, lo dirige en su desarrollo económico. Lo que domina y caracteriza esta concepción, es la fórmula de control frente a la fórmula administración directa»'s.

La base del Protectorado descansaba en el principio que «los moros no deben ser mandados más que por moros» ${ }^{10}$ y ahí radicaba una de las principales complejidades del mismo. Lo cierto es que la intervención no existió como tal durante los primeros años, en los que predominó el gobierno directo. Hasta la más o menos completa dominación de la Zona, en 1927, no se implementó realmente el régimen de protectorado y así lo reconoció la Delegación de Asuntos Indígenas en tiempos de la II República: «Durante los primeros años de protectorado la acción interventora en las kabilas era tan directa, que muchas veces fundíase el control con el mando de la vida indígena» ${ }^{11}$. La intervención requería la existencia de autoridades marroquíes que acataran al Majzen jalifiano y una actitud favorable de las autoridades protectoras para respetarla. Ninguna de las dos condiciones se dio hasta que se aseguró la sumisión de las cabilas; con excepción de las principales ciudades de la Zona, en las que la actuación de sus autoridades, que sí reconocían el Protectorado, era supervisada por los cónsules españoles.

Esta actitud de las autoridades españolas ya se había manifestado incluso antes de la firma del convenio hispano-francés de 1912. La progresiva expansión española en la región oriental a partir de 1908 topó con el inconveniente de que las cabilas próximas a Melilla distaban mucho de reconocer la autoridad del Sultán en todos sus asuntos y de acatar, por lo tanto, los acuerdos suscritos en el Acta de Algeciras (7-4-1906) ${ }^{12}$.

9 LECLERC, Max: Au Maroc avec Lyautey (mai 1921), Paris, Armand Colin, 1927, p. 116.

10 García Figueras, Tomás: «Las oficinas de Intervención Militar» en Anuario-Guía Oficial de Marruecos. Zona española. Zona Internacional. Posesiones españolas en el Norte de Africa. Gibraltar, Madrid, Editorial Ibero-Africana-Americana, 1924, pp. 263-271/263.

11 Delegación De Asuntos Indígenas: Orientaciones a los Interventores en la labor de Protectorado en Marruecos, Tetuán, s.e., 1935, $2^{\mathrm{a}}$ ed., pp. 19-20.

${ }^{12}$ La Conferencia internacional de Algeciras fue convocada, oficialmente, con el fin de introducir reformas basadas en el triple principio de soberanía del sultán, de integridad de Marruecos y de libertad económica, encaminadas a asegurar la estabilidad y el desarrollo del país. Los acuerdos incluían la organización de la Policía, la reglamentación de los impuestos y la creación de otros nuevos, la regulación de los servicios públicos y las obras públicas, la lucha contra el contrabando de armas, la organización de las aduanas del imperio, la persecución del fraude y del contrabando y la creación de un Banco del Estado marroquí. El texto del Acta puede consultarse en Gómez- 
A pesar de que en el Preámbulo del Acta se reafirmaban los principios de soberanía, independencia e integridad territorial -lo que parecía salvar el statu quo del Imperio marroquí-, los asuntos fundamentales se reducían a abordar dos cuestiones que dificultaban la penetración europea —el mantenimiento de la seguridad y del orden internos y los problemas económicos y financieros del Imperio - y el texto organizó un protectorado franco-español de hecho, bajo un vago control internacional, que ponía fin a la soberanía del sultán ${ }^{13} \mathrm{y}$, a medio plazo, permitió acelerar la captura del país y de sus recursos por las potencias europeas ${ }^{14}$.

La preeminencia de Francia y España en las cuestiones referidas al orden interno - el Acta estableció la organización de policía, bajo la autoridad del sultán y formada por musulmanes marroquíes en los ocho puertos abiertos al comercio, a cargo de instructores franceses y españoles- permitió a estos países extender su influencia y adquirir una posición privilegiada, económica y políticamente, contraria a la política del statu quo. Francia, al creerse respaldada diplomáticamente, desarrolló una estrategia de ocupación militar que justificó aludiendo a los acuerdos de Algeciras y a la anarquía reinante en el imperio. Por su parte, España, utilizando similares excusas y para evitar injerencias de ésta en su área de influencia, ocupó La Restinga y Cabo de Agua, en 1908, y el año siguiente otros territorios en las proximidades de Melilla, con objeto de proteger los trabajos mineros que desarrollaban diversas compañías privadas.

A partir de aquellos momentos, las autoridades españolas, alentadas desde sectores colonialistas radicales, promovieron el gobierno directo en los territorios ocupados ${ }^{15}$. El Real Decreto 31-12-1909, que organizó la Policía Indígena de Melilla, señaló que sus misiones consistían en «atender a la conservación del orden, a los servicios de policía militar y demás que se les encomienden» - la cursiva es nuestra - en los territorios ocupados. De este modo, quedaba abierta la puerta al ejercicio de las más variadas atribuciones, como se pondría de manifiesto en el Real Decreto 5-1-1912, que creó una Subinspección de Tropas y Asuntos Indígenas en Melilla. En su Exposición se especificaba que los jefes de las Oficinas Destacadas de Policía Indígena, dependientes de la Subinspección, ejer-

JORDANA SOUZA, Francisco: La tramoya de nuestra actuación en Marruecos, Madrid, Editora Nacional, 1976 , pp. 252-272.

13 Benjelloun, Abdelmajid: Approches du colonialisme espagnol et du mouvement nationaliste marocain dans l'ex-Maroc khalifien, Rabat, Okad, 1990, $2^{2}$ ed., pp. 29-53/49 y LAROU1, Abdallah: Esquisses historiques, Casablanca, Centre Cultural Arabe, 1992, p. 78.

14 MORAles LeZCANO, Víctor: El colonialismo bispano-francés en Marruecos (1898-1927), Madrid, Siglo XXI, 1976, p. 52.

15 Cándido Lobera consideraba que una actuación a medio camino entre la gestión majzeniana y la española -enfoque del régimen de protectorado-, ocasionaría graves inconvenientes a las autoridades españolas en Marruecos, que no podrían actuar con «el desembarazo y libertad necesarios para el mejor éxito". En su opinión, una actuación «genuinamente española» sería «la que puede dar mejores frutos y restablecer con más rapidez la normalidad en los territorios vecinos a Melilla». Véase LOBERA GiRela, Cándido: El Problema Rifeño, Melilla, El Telegrama del Rif, 1909, pp. 34-35. 
cerían «la autoridad gubernativa, como delegados del Capitán General de la Región», sobre los poblados bajo su control. Por su parte, la propia. Subinspección fue un poco más allá y, en noviembre del mismo año, dictó unas instrucciones para concretar el cometido de la Policía Indígena entre las que se encontraba «la administración de la justicia en primera instancia» ${ }^{16}$. Ambos textos legales adjudicaban funciones a la Policía Indígena que sobrepasaban las atribuciones acordadas en el Acta de Algeciras y traslucían una orientación de la política colonial española muy alejada de los principios del régimen de protectorado.

Tras la firma del convenio hispano-francés de 1912, la Real Orden 27-2-1913 estableció los diferentes órdenes de funciones que habrían de ejercerse por la intervención española: «central» — cerca del jalifa-, «especial»—en determinados ramos de la Administración (Aduanas, Obras Públicas, Correos y Telégrafos, Servicios sanitarios, etc.) - y «regional y local» —que se implantarían y desarrollarían «según las circunstancias lo consientan». La intervención política y administrativa en las ciudades - Tetuán, Larache, Arcila y Alcazarquivir- quedaría en manos de los cónsules, a la manera implantada inicialmente por Francia en su Zona; mientras que fuera de las mismas, en «las comarcas ocupadas militarmente», correría a cargo de los jefes de las Fuerzas militares

Respecto a «la central» y «la especial», que eran ejercidas cerca de las autoridades majzenianas centrales, no existían serios impedimentos para aplicarla - como tampoco en las ciudades-, pues eran ámbitos en los que las autoridades marroquíes aceptaban el establecimiento del Protectorado; pero la resistencia de las cabilas a soportarlo y a reconocer la autoridad del Majzen jalifiano sirvió de excusa para posponer temporalmente un verdadero sistema interventor en el campo.

A pesar del redactado de la Real Orden, no parece que las autoridades militares fueran muy proclives a desarrollar el sistema, pues el Real Decreto 24-7-1913, que estableció el cargo de inspector de las Oficinas de Información y Asuntos Indígenas, dispuso que éste debía asegurar que no se ejerciera un sistema de «administración directa» en las zonas sometidas ${ }^{17}$. El Real Decreto insinuaba claramente que los oficiales de la Policía Indígena actuaban incumpliendo los principios en los que se basaba el Protectorado, tal como criticó el diputado liberal Miguel Villanueva quien, tras un viaje por la Zona en 1913, denunció que los funcionarios y las autoridades españolas ejercían el gobierno directo ${ }^{18}$.

${ }^{16}$ Archivo General de la Administración -en adelante AGA-Caja M-1.485

17. Sobre la organización de las Intervenciones a lo largo del Protectorado véase VILLANOVA, José Luis: La organización politica, administrativa y territorial del Protectorado de España en Marruecos (1912-1956). El papel de la Intervenciones, op. cit., vol. 1, pp. 257-297 y VillaNOVA, José Luis: El Protectorado de España en Marruecos (1912-1956): organización política y territorial, Barcelona, Bellaterra, 2004.

18 BALFOUR, Sebastian: Abrazo mortal. De la guerra colonial a la Guerra Civil en España y Marruecos (1909-1939), Barcelona, Península, 2002, p. 91. En la Zona francesa, en la primera época del Protectorado, los oficiales de Renseignements también solían aplicar el sistema de administración 
No obstante, el defecto no era responsabilidad exclusiva de las autoridades militares, pues las directrices de la política general elaboradas en Madrid tampoco ofrecían los medios efectivos para implantar realmente la intervención. Así se desprende de la petición de la Liga Africanista al presidente del Consejo de Ministros, Eduardo Dato Iradier, solicitando que «las directivas de administración y gobierno respondan al fundamental concepto jurídico de este régimen de protectorado, tal y como se define y estatuye en los compromisos internacionales» ${ }^{19}$. Las reclamaciones en defensa del régimen de protectorado no sólo obedecían a la necesidad de respetar los acuerdos internacionales, sino que en ellas también influían razones de carácter más práctico: atenuar el rechazo de los marroquíes a «soportar gentes extrañas» ${ }^{20}$ o evitar que los hipotéticos fracasos que pudiera comportar una administración directa repercutieran negativamente sobre la imagen de España,

«de este modo será siempre la acción indígena cuando no acierte la que se gaste, la que fracase, la que incurra en responsabilidad, quedando reservada la del país protector para reparar la omisión o el daño en cada caso» ${ }^{21}$.

El Real Decreto 24-7-1913 no sirvió para modificar el sistema practicado por los oficiales de la Policía Indígena pues, en enero de 1915, el ministro de Estado, Salvador Bermúdez de Castro y O'Lawlor, marqués de Lema, dirigió una carta a la Comandancia General de Melilla en la que manifestaba su preocupación por la escasa implantación del "régimen normal del Protectorado". en la zona oriental y reclamaba el establecimiento de una estructura interventora en las cabilas de Guelaya, Quebdana y Ulad Settut que incluyera el nombramiento de caídes y la concesión de atribuciones interventoras a los jefes mi-

\footnotetext{
directa. Tal vez, en muchos de ellos influyera que habían servido en los Bureaux Arabes de Argelia, territorio en el que se implantó este sistema. Véase MERAUD, Marc: Service des Affaires Indigènes du Maroc, Arcueil, La Koumia, 1990, 461 p.

19 Liga Africanista Española: «Exposición dirigida al Sr. Presidente del Consejo de Ministros, a la que hace referencia el Acta de la Sesión celebrada en 29 de Diciembre de 1913, sobre organización en dicha Presidencia de un Centro Directivo y un Real Consejo del Protectorado en Marruecos» en África Española. Revista de colonización, industria, comercio, intereses morales y materiales (Madrid) 11 (1914) pp. 33-44/33. La aparente preocupación de la Liga por «los compromisos internacionales» merece ser matizada. El año anterior había propuesto el establecimiento dos regímenes administrativos y fiscales distintos: los territorios ocupados por las tropas españolas con anterioridad al establecimiento del Protectorado -los comprendidos «entre Cabo de Agua y el Kert, por un lado, y el Uad Femel, por el otron- debían gozar de un sistema diferente al de protectorado, pues habían sido conquistados y constituían «verdaderas zonas de natural y primera expresión» de Ceuta y Melilla. Véase MARTOS O'NEALE, José: "Política y administración de España en su zona de influencia en Marruecos» en África Española. Revista de colonización, industria, comercio, intereses morales y materiales (Madrid), 2 (1913) pp. 113-135/134.

20 Garriga Massó, Juan: «La Acción Española en Marruecos» en A.A.V.V.: La cuestión de Marruecos, Barcelona, Publicaciones de la Sociedad de Geografía Comercial, 1912, pp. 23-71/48.

21 LÓPEZ FERRER, Luciano: Naturaleza jurídica del protectorado español en Marruecos, op. cit., p. 34.
} 
litares de las oficinas. El ministro defendía su propuesta aludiendo a las posibles ambiciones territoriales de otros países durante la I Guerra Mundial. En su opinión, la nueva organización serviría para afianzar los derechos de España ante las otras naciones, pues

«mientras esa región esté sujeta tan solo a una ocupación militar nuestros derechos en ella serán sólo en precario y más susceptibles de someter a discusión que si en ellos se desenvuelve ordenadamente el Protectorado» ${ }^{22}$.

Aunque únicamente mencionaba esta circunstancia, también pudo influir en su proposición que durante la segunda mitad de 1914 la relativa tranquilidad existente en la zona oriental y el reforzamiento de las posiciones españolas facilitaban la compra sistemática de tierras en el Garet y el establecimiento de colonos españoles ${ }^{23}$. La organización de la nueva estructura permitiría sustraer a estos civiles de la jurisdicción militar y afianzar el Protectorado.

El general Francisco Gómez Jordana, comandante general de Melilla, se mostró reacio a aceptar la iniciativa del ministro, a pesar de que la propuesta preveía que los oficiales del Ejército - por ser presuntamente, en razón de sus destinos, quienes tenían un mayor conocimiento del país - pusieran en práctica el sistema de intervención. La máxima autoridad de la zona de Melilla manifestó que el establecimiento de un nuevo régimen administrativo y político, intercalado con el que ya estaba organizado, dificultaría el funcionamiento de la estructura existente

«y haría perder la unidad que hoy tiene el despacho de los asuntos indígenas en ese territorio, con el consiguiente trastorno para la acción política, que sufriría un retroceso considerable con su cambio de sistema, orientación y procedimientos».

En su opinión, la transformación debía hacerse por «zonas de gran extensión" y hasta que no se ocupara la mayor parte de Beni Buiahi, el norte de Metalsa, Beni Said, Beni Ulichec y Tafersit no llegaría el momento de establecer el nuevo régimen ${ }^{24}$. En aquellos momentos, Gómez Jordana defendía el mantenimiento del régimen dibujado por la Real Orden Circular 31-7-1914 que encomendaba a los oficiales de la Policía Indígena la administración directa de las cabilas en las que no existieran autoridades reconocidas por el Majzen.

La carta y la respuesta eran una muestra de la rivalidad que mantenían los defensores del régimen de protectorado y los partidarios de la administración directa y reflejaban las dificultades para lograr la sumisión de las cabilas al

${ }_{22}^{2}$ AGA Caja M-1.478.

${ }^{23}$ Madariaga, María Rosa de: España y el Rif. Crónica de una bistoria casi olvidada, Melilla, Ciudad Autónoma de Melilla \& Universidad Nacional de Educación a Distancia - Centro Asociado de Melilla, 1999, pp. 241-256.

${ }^{24}$ AGA Caja M-1.478. 
Majzen jalifiano y la indefinición de la política colonial española. La reticencia de las autoridades militares a nombrar autoridades majzenianas en las cabilas, argumentando que la situación militar no lo aconsejaba, ponía de manifiesto el carácter que deseaban dar a la presencia española, por el momento, y el incumplimiento de los términos del convenio de 1912.

Las razones esgrimidas por el comandante general de Melilla no convencieron al Ministerio de Estado y, en enero de 1916, el nuevo ministro, Miguel Villanueva Gómez, se dirigió a Gómez Jordana —quien desde julio del año anterior ocupaba el cargo de alto comisario- insistiendo en que había llegado el momento de implantar en la zona de Melilla «la organización de nuestro Protectorado, nombrando caídes y haciendo todo lo que correspondiera a este fin» ${ }^{25}$. La necesidad de impulsar la acción política en las cabilas y sustraerla de la jurisdicción militar - poco proclive a desarrollarla conforme a los principios de protectorado- quedó plasmada en el Reglamento Orgánico para la administración del Protectorado, aprobado por el Real Decreto 24-1-1916; aunque reafirmó la dualidad civil/militar del sistema interventor, como veremos más adelante. El Reglamento confirmó que los jefes de las Oficinas de Asuntos Indígenas eran los encargados de ejercer la intervención en los «territorios no pacificados», pero para ello actuarían «con arreglo a las inspiraciones que reciban del Delegado de Asuntos indígenas» —un miembro de la Carrera diplomática o consular-, y no de las Comandancias Generales como hasta entonces. Sin embargo, el régimen de protectorado apenas se desarrolló en el campo - a pesar de que su implantación en algunas zonas fue solicitada dos años más tarde por el alto comisario, Gómez Jordana, a los ministros de Estado, Álvaro de Figueroa y Torres, conde de Romanones, y de la Guerra, general Dámaso Berenguer - ${ }^{26}$ y la administración directa continuó siendo el sistema de gestión predominante.

Aun en el caso de aceptar que la acción militar fuese considerada necesaria en las condiciones en las que se intentaba extender el Protectorado, el error consistió en que ésta fuera una acción «preponderante» y que dejara «poco campo de acción al Protectorado, cuyo territorio, fuera del ocupado por las cuatro ciudades del mismo, quedó sujeto a la administración directa de las autoridades militares» ${ }^{27}$. En la misma opinión abundaron otros autores que criticaron que en la zona oriental no se hubiera dotado del prestigio debido la autoridad de los caídes, ni fomentado la agricultura ni las obras públicas, ni establecido una eficaz administración civil y militar, ni un buen servicio de justicia, ni levantado escuelas, ni una organización sanitaria, etc. ${ }^{28}$

\footnotetext{
25 AGA Caja M-78.

${ }^{26}$ GÓMEZ-JORDANA SOUZA, Francisco: La tramoya de nuestra actuación en Marruecos, op. cit., pp. 34-35.

27 LÓPEZ FERRER, Luciano: Naturaleza jurídica del protectorado español en Marruecos, op. cit., pp. 35-36.

28 PITA, Federico: El Amalato del Rif, Melilla, Artes gráficas Postal Exprés, s.a. [1925], p. 43.
} 
Esta situación era el resultado de que una auténtica política de protectorado no estuviera «mas que en los labios de algunas gentes, en las intenciones, estamos por decir que de nadie. Los de arriba, como los de abajo, civiles y militares, todos pensaron en una nueva colonia». En tiempo de paz se actuaba «como en país conquistado» y solamente cuando surgían complicaciones militares "salía tal o cual representante del país hablando del tema del protectorado» ${ }^{29}$. Dicho de otro modo, faltaban «conocimientos políticos, en sus directores y más aún, por desconocer lo que era un protectorado, una labor de penetración, de creación de intereses, de espíritu de paz». Quienes llevaban a cabo la acción española carecían «del sentido político necesario para crear, a retaguardia de las líneas militares, una vida de aspecto económico, base de la paz y del Protectorado» 30 .

Estos criterios chocaban con los defendidos por Cándido Lobera, quien consideraba que lo esencial de la actuación española tenía que ser «el prestigio del país protector; y como primero y principal de sus factores, el reconocimiento de que somos los más fuertes en todos los órdenes» ${ }^{31}$. La preponderancia de los militares partidarios de una penetración basada en el uso de la fuerza y la ausencia de planteamientos claros en la Metrópoli impidieron que durante los primeros años se desarrollara una política acorde con los principios del Protectorado.

El desastre de Annual (22-7-1921), que supuso el desmoronamiento de la Comandancia General de Melilla y la pérdida de los territorios conquistados por España en la región oriental, obligó a replantear la política desarrollada en la Zona. El 22 de agosto de 1922, el recién nombrado alto comisario, general Ricardo Burguete Lana, remitió al ministro de Estado, Joaquín Fernández Pri$\mathrm{da}$, un proyecto de real decreto en el que subrayaba la necesidad de

«remover los obstáculos de carácter legislativo que pueden detener o entorpecer la rápida y gradual implantación del Protectorado en aquellas regiones que, según mi modesto juicio, se encuentran ya en sazón para gozar y vivir en un régimen meramente majzeniano» 32 .

En este sentido, el Real Decreto 16-9-22 anunció la implantación del sistema de intervención civil en las zonas más pacificadas; mientras que el resto continuarían intervenidas por militares. A pesar de referirse a la intervención en ambas zonas, el Real Decreto concretaba que el régimen civil implicaba «el reconocimiento del derecho que asistirá a sus habitantes para regirse por sus

29 Ruiz Albéniz, Víctor: España en el Rif (1908-1921), Melilla, Ayuntamiento de Melilla, 1994, ed. facsímil , pp. 225-226.

30 Pita, Federico: Del Protectorado Español en Marruecos. Unos cuantos meses de observación en la Capital de la Zona Española, Melilla, Gráficas La Ibérica, 1933, p. 15.

3! El comentario ha sido extraído del artículo «Modalidades de la Administración» incluido en el dossier Política Rifeña del Protectorado -conjunto de tres artículos publicados por Cándido Lobera en 1925-, localizable en la Biblioteca Nacional, fondo «África», signatura GF Caja 67-a.

32 AGA Caja M-24. 
propias leyes y autoridades, mediante la oportuna inspección del Interventor civil». Asimismo, el artículo $4^{\circ}$ precisaba que su implantación comportaba el nombramiento de autoridades majzenianas que contarían con la asistencia de los interventores civiles. Como estas precisiones no se hacían extensivas explícitamente a las regiones bajo intervención militar puede inferirse que todavía no existía la intención de implantar el régimen de protectorado en las mismas.

En uso de las prerrogativas que le concedía el Real Decreto, el alto comisario solicitó, a las Comandancias Generales de Ceuta, Melilla y Larache, informes acerca de las cabilas en las que podía establecerse la intervención civil. Sin embargo, las presiones que desde éstas se ejercieron limitaron su implantación. Al margen de la delicada situación por la que pasaba la Zona, las presiones obedecían al interés de numerosos sectores militares de no perder el control de las áreas que administraban, sin apenas restricciones, y al rechazo que manifestaban acerca de un sistema que impedía el ejercicio de la administración directa. Incluso se hicieron llamamientos a desentenderse de los acuerdos internacionales «de la manera más hábil que sea posible, incluso por la fuerza», ante las limitaciones que imponían ${ }^{33}$.

A finales de 1922, el secretario general López Ferrer denunció estas presiones y criticó que se hubiera renunciado a implantar el régimen civil en Anyera, Uadrás, Guelaya, Quebdana y Ulad Settut con la excusa de que no estaban preparadas. López Ferrer consideraba esta decisión como un «enorme salto atrás» y recordaba que las dos últimas habían sido las cabilas más pacíficas de la Zona y que habrían continuado fieles en 1921 si no las hubiesen abandonado los oficiales de la Policía Indígena y los destacamentos militares. Respecto a la de Anyera señalaba que era «la que con más lealtad se ha conducido desde su sumisión»; aunque acontecimientos posteriores demostrarían lo erróneo de esta última apreciación. En su opinión, la resistencia de las cabilas

«y sobre todo la virulencia con que se manifestó la insurrección de las del territorio contiguo a Melilla, obedece muy principalmente —aparte de otros motivos- a un sentimiento antimilatarista y al profundo odio que inspira a todos los cabileños la Policía Indígena».

Según el secretario general, era previsible el levantamiento del Rif

«para todos los que prestaban alguna atención al desarrollo de nuestra acción en la comarca próxima a Melilla, presentada a España como una Arcadia por los Comandantes Generales, secundados por una prensa local asalariada y unos corresponsales de la prensa de la península, tinglado que maneja allí un oficial de Artillería, llamado Lobera, diestrísimo acaparador de subvenciones y maestro en

33 MAESTRE, Pedro: Divulgación y orientación del problema de Marruecos. Intervención Civil, Intervención Militar, Granada, Imprenta del diario La Publicidad, 1923, p. 175.

Hispania, LXV/2, núm. 220 (2005) 683-716 
el arte de defender aquel estado de cosas que tan desagradable epílogo tuvo en Annual».

Para López Ferrer dichos sectores habían desvirtuado la realidad defendiendo que los rifeños no querían ser gobernados por caídes suyos, sino que los «gobernaran los inconscientes, livianos mozalbetes de la Policía Indígena». En una palabra, que deseaban «el gobierno directo de España y ejercido por militares precisamente» ${ }^{34}$.

Al margen del rechazo de las cabilas rifeñas a aceptar el nombramiento de autoridades representantes del Majzen jalifiano, al que López Ferrer no hacía referencia, lo cierto es que parece ser que los oficiales de la Policía Indígena no se esforzaron en absoluto para implantar el sistema de protectorado.

López Ferrer continuó reclamando el establecimiento de un verdadero régimen de protectorado y durante el breve periodo de tiempo que ocupó interinamente el puesto de alto comisario ${ }^{35}$ envió un escrito al ministro de Estado, Santiago Alba Bonifaz, requiriendo que se implantase de una vez, conforme a lo dispuesto en el Real Decreto 16-9-1922. En el escrito denunciaba que el sistema de protectorado o no se había aplicado o se ejercía «indebidamente», aplicándose en su lugar «la administración y gobierno directo del país protegido por el protector». López Ferrer realizaba una ardiente defensa del régimen civil de la intervención al que identificaba con el de protectorado: el caíd debía ser responsable de cuanto ocurriera en la cabila, para lo que debía contar con «elementos de represión» propios y únicos - ya que la presencia de otras fuerzas indígenas ajenas a su autoridad constituían «elementos disolventes» de su prestigio y de su autoridad-y el interventor no debía limitarse a la vigilancia de las autoridades, sino que tenía que procurar el desarrollo económico de su jurisdicción. Con la finalidad de extender progresivamente el régimen de protectorado presentó un posible plan de organización de la acción interventora — «atendiendo a la densidad de población, extensión territorial y, sobre todo, a la tradición musulmana»-y propuso la supresión de la Comandancia General de Larache, a la que consideraba un obstáculo para el normal establecimiento del Protectorado en la región occidental, y la implantación de la intervención civil en el Bajalato de Tetuán, la ciudad de Chauen y las cabilas del Hauz, Beni Hozmar, Anyera y Uadrás ${ }^{36}$. Sus propuestas sólo fueron aceptadas parcialmente ${ }^{37}$ y López Ferrer dimitió del cargo de secretario general el 23 de abril de

${ }^{34}$ AGA Caja M-20.

35 El 2 de enero de 1923, Miguel Villanueva Gómez fue nombrado alto comisario, pero por enfermedad no llegó a tomar posesión del cargo. El puesto fue ocupado interinamente por el secretario general, López Ferrer, hasta el 17 de febrero; fecha en la que fue nombrado otro alto comisario civil, Luis Silvela Casado.

36 AGA Caja M-24.

37 A finales del año 1923, la Intervención civil se había implantado en las cabilas de Guelaya y Quebdana y Ulad Settut, en la zona oriental, y en la Garbía, Sahel, Jolot, Jolot y Tilig, Anyera, El 
1923. En su decisión también debieron influir las presiones de determinados sectores militares con los que estuvo permanentemente enfrentado.

La instauración del Directorio Militar de Primo de Rivera (15-9-1923) comportó el final de los ensayos "civilistas» y una nueva orientación de la política sobre la Zona. Primo de Rivera subrayó la preeminencia de la acción militar sobre la civil en las circunstancias por las que pasaba la Zona, aunque no excluyó «una activísima y eficaz acción de protectorado donde ésta se pueda implantar» ${ }^{38}$. En las "Líneas generales que el Directorio deseaba se tuvieran en cuenta por el Alto Comisario, general en jefe, para su actuación» (21-9-1923) concretó los aspectos que debía comprender la intervención civil: colonización, obras públicas, enseñanza, organización majzeniana, estadísticas, cobro de impuestos, etc.; elementos que ponen de manifiesto que Primo de Rivera también identificaba el sistema de intervención civil con el de protectorado. También animó al alto comisario, teniente general Luis Aizpuru Mondéjar, a preparar la implantación del régimen civil en la región oriental, para lo que debía organizar el mando indígena, aunque bajo la intervención ejercida por militares temporalmente. Respecto a la región occidental le proponía revisar las zonas que podrían pasar a ser administradas bajo intervención civil ${ }^{39}$.

A pesar de esta declaración de intenciones, la grave situación militar por la que pasó la Zona en los primeros meses de 1924 y la orientación claramente militarista del Directorio provocaron una progresiva reducción de los territorios colocados bajo el régimen de protectorado.

Las operaciones desencadenadas tras el desembarco en Alhucemas (8-91925) y la firma del convenio hispano-francés de marzo de 1926, que facilitó la coordinación de posteriores campañas militares, comportaron la sumisión de numerosas cabilas. En aquellas circunstancias la implantación del régimen civil se contempló como un medio para extender el régimen de protectorado, necesario para prestigiar la imagen del Majzen jalifiano en las cabilas y atraer a determinados sectores de la resistencia ${ }^{40}$. El término «régimen civil» volvía a

\footnotetext{
Hauz, Uadrás y una parte de Beni Hozmar en la zona occidental. Pero la Administración metropolitana no fue receptiva a la propuesta de limitar la presencia militar en las cabilas intervenidas civilmente a las fuerzas del caíd. Véase AGA Cajas M-1.251 y M-1275.

38 GÓMEZ-JORDANA SOUZA, Francisco: La tramoya de nuestra actuación en Marruecos, op. cit., p. 56.

39 GómEZ-JORDANA SOUZA, Francisco: La tramoya de nuestra actuación en Marruecos, op. cit., p. 58-59. Paralelamente, Primo de Rivera mantenía contactos con diferentes grupos colonialistas, como la Liga Africanista, para que respaldaran su actuación y le proporcionaran orientaciones que sirvieran para guiar su política en Marruecos. Respecto a la acción interventora, la Liga insistió en que se respetase a los «jefes naturales del país», aunque «siempre orientando y vigilando su gestión mediante el empleo de interventores, militares en las kabilas de contacto y en las levantiscas, y civiles en las perfectamente sometidas». Véase LIGA AFRICANISTA ESPAÑOLA: «Documento elevado por la Liga Africanista a Primo de Rivera (Presidente del Directorio)» en Revista Hispano Africana (Madrid), 11-12 (1923), p. 325.

40 En este sentido, por Real Orden Circular 29-7-1926 se solicitaron informes a la Inspección General de Intervención Militar sobre las cabilas susceptibles para implantar el régimen de protec-
} 
hacer referencia sencillamente a lo que debía ser «régimen de protectorado", frente al de «administración directa». Al menos eso se desprende de un informe de la Dirección de Intervención Civil en el que aclaraba que en los territorios donde se implantase el régimen civil «la obra a realizar ha de asentarse en bases fundamentales de Protectorado» y debía reconocerse la capacidad del Majzen para gobernar a sus súbditos conforme a las tradiciones del país, tal y como prescribía el convenio de $1912^{41}$.

La "pacificación» ${ }^{42}$ abrió la puerta a la extensión del régimen de intervención y es a partir de aquel momento cuando puede hablarse, teóricamente, de respeto a los principios del Protectorado. No obstante, las continuas referencias al significado de la intervención en disposiciones oficiales, circulares de la Delegación de Asuntos Indígenas, textos de formación de los interventores y artículos diversos permiten asegurar que no siempre se respetaba su auténtico significado. A modo de ejemplo, podemos señalar que el Decreto 16-6-1931 incluyó un artículo adicional en el que se encomendaba al alto comisario que propusiese el establecimiento de un régimen civil en los territorios pacificados, el cual debía incluir la «mejora de sus instituciones majzenianas y con respeto a la tradición del país protegido en lo que sea digno de conservación"; aspectos que ya se encontraban contemplados en el convenio de 1912. Por otra parte, en 1935 el delegado de Asuntos Indígenas, coronel Fernando Capaz y Montes, insistió en que

«la Intervención precisa juicio acertado, dándose perfecta cuenta el funcionario que la ejerce de que nuestra misión es de protectorado y tutela. Por ello lo necesario es un control e inspección de las autoridades del país que no derive en la acción directa, llegando a entrometerse en lo que es competencia única de las autoridades naturales con absorción de las facultades a ellas conferidas» 43 .

Tras la Guerra Civil, la actuación española parece ser que adoptó formas mínimamente respetuosas con los principios del Protectorado, al menos en comparación con la Zona francesa. En este sentido se han manifestado algunos autores extranjeros quienes han asegurado que, muy a menudo, la gestión en la

torado. La Inspección propuso que se estableciera inmediatamente en Guelaya, Quebdana, Ulad Settut y Beni Buiahi, en la zona oriental, y en Jolot y Tilig y Garbía, en la zona de Larache. A ellas podrían sumarse en plazo próximo Sahel, Anyera y El Hauz. Véase AGA Caja M-1.251.

${ }^{41}$ AGA Caja M-1.478.

42 El término "pacificación» y sus derivados comenzaron a utilizarse frecuentemente desde los primeros años del Protectorado. Su significado real no es otro que designar «el conjunto de operaciones militares que las autoridades coloniales se ven obligadas a desarrollar con el objetivo de ocupar la totalidad del país a someter y aniquilar, por la vía de la consecuencia, toda resistencia armada actual o potencial de las fuerzas autóctonas". Véase BENJELLOUn, Abdelmajid: Approches du colonialisme espagnol et du mouvement nationaliste marocain dans l'ex-Maroc khalifien, op. cit., p. 67.

43 CAPAZ y MONTES, Fernando: «La obra de las Intervenciones» en La Gaceta de África (Tetuán) número extraordinario dedicado a la obra de España en Marruecos (1935), pp. 11-12/11. 
Zona española podía ser considerada «indirect rule» 44 . No hay que olvidar que las autoridades franquistas estuvieron dispuestas a respetar, al menos formalmente, la concepción del Protectorado siempre que no entrara en conflicto con los intereses de la Metrópoli. España debía actuar en Marruecos con el

«respeto más absoluto de su religión, costumbres y particularidades, en tanto no perjudique a la comunidad de ideales y a la misión que ambos pueblos unidos estamos llamados a desempeñar en el mundo»45.

\section{INTERVENCIÓN MILITAR O INTERVENCIÓN CIVIL}

Desde el inicio del Protectorado se manifestaron dos concepciones antagónicas sobre la idoneidad de que fuera personal militar o civil el encargado de ejercer la labor interventora. Por otra parte, durante los primeros años llegaron a confundirse «intervención civil» con «régimen de protectorado» e «intervención militar» con "administración directa», como hemos visto. Estas posturas reflejaban una pugna entre sectores «civilistas" y militaristas por controlar la gestión del Protectorado y dos maneras diferentes de entender la presencia española en Marruecos.

La resistencia de las cabilas a la implantación del Protectorado fue el factor que determinó que la intervención política y administrativa fuese ejercida inicialmente, bajo la dependencia del alto comisario, por los jefes de las Fuerzas Militares en las comarcas ocupadas militarmente, y por los cónsules en las ciudades de Tetuán, Larache, Arcila y Alcazarquivir ${ }^{46}$. El Reglamento Orgánico de 1916 confirmó el fraccionamiento del sistema interventor -alto comisario/jalifa, delegado de Asuntos Indígenas/autoridades que no se reservara el primero y las marroquíes de Tetuán, cónsules/autoridades marroquíes de las ciudades y jefes militares de las oficinas de Asuntos Indígenas/territorios no pacificados-, aunque subrayó su carácter político y subordinó la acción interventora que desarrollaban los cónsules y las Oficinas de Asuntos Indígenas militares al delegado de Asuntos Indígenas en primera instancia.

El modelo se inspiraba en el implantado por Francia en su Zona, pero ofreció diferencias notables. En la Zona francesa, la intervención quedó bajo la responsabilidad de contrôleurs civils — según el modelo organizado en Túnez en 1884 - y de officiers des Affaires Indigènes, pero la dirección de la política indí-

${ }^{44}$ Pascon, Paul y Wusten, Herman van der: Les Beni Bou Frah. Essai d'écologie d'une vallée rifaine (Maroc), Rabat, Institut Universitaire de la Recherche Scientifique \& Faculté de Géographie Sociale de l'Université d'Amsterdam \& Institut Agronomique et Vétérinaire Hassan II, 1983, p. 104.

45 ARANDa MATA, Antonio: «Presente y porvenir de Marruecos» en África. Revista Española de Colonización (Madrid) 1 (1942), pp. 3-9/9.

46 Véanse las Reales Ordenes 27-2-1913 y 24-4-1913.

Hispania, LXV/2, núm. 220 (2005) 683-716 
gena no sufrió la dualidad de mando que, de hecho, se instauraría durante años en la española. Por otro lado, las circunscripciones a cargo de civiles se extendieron mucho más rápidamente que en la Zona española, en la que los interventores civiles vieron limitada su acción a las ciudades, hasta bien avanzado el Protectorado. El mismo año de la firma del convenio franco-marroquí de 1912, el embajador Regnault propuso que en las zonas donde existieran intereses europeos considerables y donde la pacificación pudiera ser conseguida fácilmente, el control de la administración marroquí debía ser confiada al elemento civil, «más preparado a tratar las cuestiones administrativas y a regular los asuntos económicos y políticos que originan los intereses extranjeros». El año siguiente, el Arrêté du Résident 22-3-13, que puede considerarse la «verdadera acta de nacimiento del control civil», creó una región civil en la Chaouia ${ }^{47}$.

Los años siguientes, algunos altos comisarios y funcionarios civiles consideraron imprescindible extender el ámbito territorial de las jurisdicciones intervenidas por civiles. Las primeras iniciativas correspondieron al alto comisario, Francisco Gómez Jordana, quien planteó en 1918 la conveniencia de combinar una política de guerra, que permitiría abrir paso a la civilización, con una indígena regulada por los organismos civiles del Protectorado, que debía aplicarse a la zona pacificada ${ }^{48}$. Gómez Jordana reclamaba el paso de las zonas pacificadas «a la administración de las autoridades del Majzen, intervenidas por los civiles del Protectorado» ${ }^{49}$. El mismo año, la Intervención Local de Nador solicitó al Ministerio de Estado que las Oficinas de Asuntos Indígenas cedieran progresivamente servicios a la Intervención Local ${ }^{50}$.

En el fondo, los demandantes consideraban que la implantación del régimen de protectorado solamente podía hacerse mediante el establecimiento de la intervención ejercida por civiles y las reclamaciones se enmarcaban en lo previsto en la Real Orden 27-2-1913: la intervención regional y local «se implantará y desarrollará según las circunstancias lo consientan». El problema radicaba en el redactado de la disposición oficial y en que eran los comandantes generales las autoridades competentes para valorar, en primera instancia, si las circunstancias permitían instaurar la intervención civil. En la mayor parte de los casos, éstos consideraban que la penetración española debía realizarse primando la acción militar - al menos en los primeros momentos- y desconfiaban de la capacidad del personal civil para ejercer las labores interventoras. $\mathrm{Al}$ margen de la pretendida idoneidad de los militares para llevarlas a cabo, su error era confundir la gestión de los civiles con el sistema de protectorado y la

${ }^{47}$ GRUNER, Roger: Du Maroc traditionnel au Maroc moderne. Le contrôle civil au Maroc. 19121956, Paris, Nouvelles Éditions Latines, 1984, pp. 205-207.

48 Alonso Baquer, Miguel: «El problema de Marruecos» en Alonso BaQuer, Miguel y HeRnÁNDEZ SÁNCHEZ-BARBA, Mario (dirs.): Las Fuerzas Armadas Españolas. Historia institucional y social, vol. 5, Madrid, Alhambra, 1986, pp. 227-257/230-233.

49 GÓMEZ-JORDANA SOUZA, Francisco: La tramoya de nuestra actuación en Marruecos, op. cit., p. 34.

so AGA Caja M-98. 
de los militares con la administración directa, modelo practicado ampliamente por las Oficinas de Asuntos Indígenas. Esta actitud impidió que el Protectorado se implantase en algunas zonas pacificadas y las negativas consecuencias no tardarían en manifestarse.

La expansión territorial española en 1919 y 1920 permitieron que algunos sectores "civilistas» de la Administración presentaran tímidas propuestas para atribuir a civiles la labor interventora de las zonas pacificadas. Hasta el momento, los cónsules eran los únicos civiles que, exclusivamente en las ciudades, intervenían la actuación de las autoridades marroquíes. Sobre el resto de las autoridades eran los oficiales de la Policía Indígena - jefes de las oficinas de Asuntos Indígenas- quienes desempeñaban esta función.

En 1919, el ministro de Estado, Manuel González-Hontoria y FernándezLadreda, consideró la necesidad de implantar el régimen civil — que identificaba con «régimen de protectorado»- para cumplir las exigencias del convenio de 1912 y consultó a las Comandancias Generales sobre qué zonas podían ser administradas bajo dicho régimen. La posibilidad de que personal civil ejerciese la actividad interventora fuera del radio de las ciudades provocó un profundo rechazo entre las autoridades militares. La Comandancia de Larache denunció que la intervención civil no funcionaba en absoluto en las ciudades, argumentando que los interventores civiles desconocían las materias de su competencia y las autoridades marroquíes actuaban con total libertad. Para fundamentar sus afirmaciones advertía que el personal de la carrera consular - los interventores en las ciudades - no se encontraba a gusto en dichos puestos y deseaba impacientemente su traslado. En su opinión, eran los interventores militares quienes actuaban con eficacia, y especialmente si se tenía en cuenta que su labor se desarrollaba en la primera etapa de la dominación, la más complicada ${ }^{51}$. El desprecio con que los militares contemplaban a los interventores civiles era extensivo a la mayoría del personal civil destinado en la Zona ${ }^{52}$.

La documentación consultada no permite corroborar las acusaciones de la Comandancia General de Larache - aunque es cierto que los destinos de cónsul en las ciudades del Protectorado no estaban demasiado solicitados por los miembros de la Carrera_ 53 y no todas las opiniones eran coincidentes. Por

\footnotetext{
s1 Informe dado por la Policía Indígena sobre el primer Proyecto de Protectorado Civil, texto mecanografiado, s.a. [1919]. Este documento puede localizarse en la Biblioteca Nacional, fondo "África», signatura GF Caja 377-17.

s2 Años más tarde, el alto comisario, Francisco Gómez-Jordana Souza, declaró al respecto: «No debo ocultar que hay algunos de ellos muy celosos del cumplimiento de su deber, inteligentes y duchos en su cometido, con preparación suficiente para ser útiles en nuestra actuación en Marruecos; pero, desgraciadamente los más, se limitan a averiguar las licencias a que tienen derecho cada año; y, cuando más, a criticar lo que hacen los demás y especialmente sus jefes». Véase GómEZJORDANA SOUZA, Francisco: La tramoya de nuestra actuación en Marruecos, op. cit., p. 35.

53 Martínez de Velasco Farinós, Ángel: «La reforma del Cuerpo diplomático por Primo de Rivera» en Revista Internacional de Sociología (Madrid) 35 (1980), pp.409-442/422 y 428.
}

Hispania, LXV/2, núm. 220 (2005) 683-716 
ejemplo, el secretario general López Ferrer - que pertenecía a la Carrera diplomática- se manifestó absolutamente partidario de que la misión interventora fuese desempeñada por los cónsules. Para defender sus argumentos citó el caso del cónsul interventor de Alcazarquivir, Julio López Oliván, quien había conseguido que la Intervención local funcionara plenamente, por lo que

«las gentes van prescindiendo de acudir a las oficinas de Policía Indígena y se dirigen a la Intervención en la que ven mejor garantizados sus derechos y donde los procedimientos son más dúctiles y atrayentes" 54 .

A su vez, el 1 de julio de 1920, el secretario general, López Ferrer, remitió un documento confidencial al ministro de Estado, Salvador Bermúdez de Castro y $\mathrm{O}^{\prime}$ Lawlor, marqués de Lema, recomendando establecer rápidamente el régimen civil en las comarcas totalmente pacificadas. No obstante, consciente de la necesidad de periodos de transición y de formación del personal civil y de las previsibles reacciones de rechazo por parte del Ejército, propuso mantener las funciones de las oficinas militares. El temor a una posible reacción adversa del Ejército, junto a la inestable situación de la Zona, pesaron tanto al secretario general que propuso descargar a la Delegación de Asuntos Indígenas de la dirección de las relaciones generales con las cabilas y de la centralización de los informes sobre su situación. En su opinión, la DAI no había desarrollado estas funciones, ni era conveniente que las asumiera en aquellos momentos. La labor informativa y hacer llegar a todos los lugares la política que marcaba el alto comisario las realizaba la Policía Indígena que contaba con personal preparado, el cual no era posible sustituir rápidamente: «intentar que esta misión pasase a manos civiles sería hoy depresiva para el Ejército, perjudicial para la buena marcha política del Protectorado, un fracaso seguro para los funcionarios civiles», pues la Delegación no se encontraba preparada para ello ni contaba con los elementos necesarios 5 . El desmoronamiento de la Comandancia de Melilla, el año siguiente, dejó la propuesta en suspenso durante algún tiempo.

Por otra parte, la pretendida eficacia de los oficiales de las oficinas de Asuntos Indígenas quedó malparada en el desastre de Annual. Víctor Ruiz Albéniz, médico militar destinado en la Zona, denunció la orientación predominantemente militarista de sus actuaciones y la desidia de su comportamiento:

«cuando no hemos ido con son de conquista militar, hemos procedido como vividores parásitos del país; pero estudiar las costumbres y leyes del moro, vivir su vida, hablar su lengua, crear vínculos e intereses comunes, eso, ni lo hemos intentado siquiera» 56 .

\footnotetext{
54 AGA Caja M-87.

55 AGA Caja M-87.

56 RUIZ AlBÉNIZ, Víctor: España en el Rif (1908-1921), op. cit., p. 34.
} 
El menosprecio con que algunos militares contemplaban el llamado «Protectorado civil» también aparece reflejado en las palabras del protagonista de la novela Imán, quien comenta que un tal comandante Ansuago «se suele ir de bureo hasta el río. Allí va una vieja con Fátima, que cobra un duro. A eso le llama ir de protectorado civil»\$57.

Los errores políticos puestos en evidencia a raíz de Annual motivaron un cambio de dirección de las orientaciones dictadas desde Madrid. El Real Decreto 16-9-1922 anunció la implantación del régimen de protectorado en las zonas pacificadas, las cuales serían gobernadas por autoridades marroquíes asistidas por interventores civiles, como hemos señalado. De este modo se ponía en entredicho la acción desarrollada por las autoridades militares, al considerar que su actitud no había facilitado el desarrollo del sistema de protectorado, y se sustraía a su autoridad directa la gestión de dichas zonas. Por otra parte, la disposición oficial estableció de hecho un doble sistema interventor: el delegado de Asuntos Indígenas adoptó el título de inspector general de Intervención Civil y Servicios Jalifianos y asumió la dirección de la política en las cabilas en las que el alto comisario decidiera implantar el régimen civil; mientras que la nueva Inspección General de Intervención Militar y Tropas Jalifianas la ejercería en el resto de las cabilas ocupadas. Para asegurar la necesaria coordinación de la política indígena, ambas Inspecciones debían mantener una constante relación, informando del estado de sus jurisdicciones al secretario general, sin embargo el redactado del Real Decreto no concretó explícitamente la dependencia de la Inspección General de Intervención Militar respecto de la Secretaría General, circunstancia que limitó la unidad de mando.

A pesar de la voluntad de los legisladores de extender el régimen de protectorado, el Real Decreto tampoco incidió en el problema de fondo: no contemplaba la posibilidad de nombrar autoridades marroquíes en las zonas bajo jurisdicción de la intervención militar y que los oficiales actuaran como auténticos interventores. En realidad no se trataba de plantear si tenían que ser funcionarios civiles o militares quienes ejercieran la intervención, sino si ésta se implantaba o no. No era correcto

«calificar de civil el protectorado cuando se ejerce por medio de funcionarios civiles; es confundir el órgano con la función. El protectorado no puede ser civil, ni militar ni eclesiástico; su acción está ejercida por el Estado protector en el conjunto de sus poderes, bien se valga del instrumento civil o militar» 58 .

Sin embargo, la nueva orientación política se vio frenada por la delicada situación bélica, por las presiones de los sectores partidarios de una acción predominantemente militar e incluso por el deficiente funcionamiento de la Ad-

57 Sender, Ramón J.: Imán, Barcelona, Destino, 1995, $5^{\text {a }}$ ed. en Destinolibro, p. 34.

58 LÓPEZ FERRER, Luciano: Naturaleza jurídica del protectorado español en Marruecos, op. cit., p. 34. 
ministración española ${ }^{59}$. A modo de ejemplo, puede mencionarse el retraso con que se efectuó la designación de los nuevos interventores civiles. En octubre de 1923, desde la Jefatura de la Mehal-la Jalifiana de Tetuán se manifestó preocupación por el retraso en los nombramientos en las cabilas Anyera y Uadrás. ${ }^{60}$ Por este motivo la intervención debía ser atendida por elementos de la Mehal-la y de otras oficinas y los desplazamientos de este personal repercutían negativamente en el cumplimiento de sus funciones originales ${ }^{61}$.

La reacción de los militaristas ante el Real Decreto no se hizo esperar y elaboraron un discurso artificioso destinado a subrayar la idoneidad de los militares para ejercer la labor interventora. Por primera vez asumieron públicamente que el Protectorado no tenía por qué ser calificado de civil o militar ${ }^{62}$ y reconocieron el carácter civil que debía tener la intervención, aunque defendieron la validez transitoria de la intervención militar por la necesidad de apoyar las primeras medidas «en una sensación de fuerza»; debían emplearse "procedimientos de energía» y «resortes militares» en las áreas rurales ${ }^{63}$. Por otra parte, para que los interventores militares no perdieran sus atribuciones, intentaron obtener el reconocimiento de la labor que habían desarrollado; como estadio previo para reclamar un mayor protagonismo en el ejercicio del Protectorado ${ }^{64}$.

59 A finales de 1923 el régimen civil solamente se había establecido en catorce cabilas. Véase AGA Cajas M-1.251 y M-1.275.

${ }^{60}$ Las Mehal-las era el nombre tradicional que se daba a los cuerpos del ejército del sultán. En la Zona española constiruyeron las fuerzas del Majzen jalifiano y formaban parte de las llamadas «fuerzas indígenas». Estas últimas estaban constituidas por las Mehal-las-, las fuerzas regulares bajo la dependencia del Ministerio de la Guerra-, las irregulares (harkas, gums, etc.), que subsistieron hasta 1927, y la Policía Indígena. Véase ASENSIO TORRADO, José: «Los ejércitos coloniales» en África. Revista de Tropas Coloniales (Ceuta) abril, mayo y junio (1931), pp. 85-90, 95-100 y 124-128, respectivamente y SOTTO MONTES, Joaquín de: «Notas para la historia de las Fuerzas Indígenas del Antiguo Protectorado de España en Marruecos» en Revista de Historia Militar (Madrid) 35 (1973), pp.117-154

61 AGA Caja M-1.275.

62 «Siendo el Protectorado una obra de asociación de todos los elementos culturales y potenciales de un país, no puede dársele otro nombre que protectorado nacional, o simplemente protectorado. Lo demás tiende a la disociación de tales elementos y mata los estímulos mejor dispuestos». Véase MAESTRE, Pedro: Divulgación y orientación del problema de Marruecos. Intervención Civil, Intervención Militar, op. cit., p. 56.

${ }^{63}$ García Figueras, Tomás: «Las oficinas de Intervención Militar» en Anuario-Guía Oficial de Marruecos. Zona española. Zona Internacional. Posesiones españolas en el Norte de Africa. Gibraltar, op. cit., p. 264

${ }^{64}$ En noviembre de 1922, el Teniente Coronel Jefe de la oficina Central de la Comandancia de Larache había manifestado que las cabilas de Sahel, Jolot, Jolot y Tilig y Garbía podían pasar a régimen civil, pues se encontraban pacificadas. Pero la necesidad de justificar la escasa labor de protectorado realizada por la Policía Indígena le llevó a señalar que el forzoso desplazamiento de dichas fuerzas a cabilas insumisas, a consecuencia de los enfrentamientos bélicos, no había permitido lograr un «conocimiento profundo» de las mismas. Por este motivo, esperaba poder acabar el infor- 
Para no perder su primacía reivindicaron que las nuevas plazas de interventores civiles fueran cubiertas preferentemente por jefes y oficiales que hubiesen desempeñado cargos en la intervención militar ${ }^{65}$. Aunque ya no ponían en duda el carácter civil de la intervención, justificaban la demanda destacando una mayor capacidad y mejores aptitudes de los militares para desarrollar esta tarea:

«la Intervención Civil no exige personal civil, sino españoles preparados para la obra, capacitados para desarrollarla y que tengan un concepto claro de su misión. Estos elementos se encuentran hoy, por razones fáciles de comprender, en mayor abundancia entre los militares, por lo cual a nadie puede extrañar que éstos desempeñen algunas Intervenciones de las sometidas a régimen civil» 66 .

La obsesión por controlar el sistema de Intervenciones era de tal magnitud que no se limitaron a ensalzar las virtudes de los militares, sino que también criticaron la labor de los civiles:

«Siempre temimos, sin embargo, lo que hoy sucede; que llevamos [los militares] demasiada delantera [...] y que cuando nosotros dijéramos: ha terminado nuestra acción más espinosa y dura, el elemento civil, salvo contadas excepciones, no se habría enterado de su deber en Marruecos» ${ }^{67}$.

Esta opinión era ampliamente compartida por otros militares. La Oficina Central de Intervención y Fuerzas Jalifianas de la Región Oriental elaboró, en octubre de 1926, un informe en el que exponía sus dudas acerca de las aptitudes de los interventores civiles ${ }^{68}$. Sus planteamientos reflejaban el sentimiento ampliamente extendido entre los sectores militares de constituir una casta aparte respecto a los civiles. Un grupo que se consideraba destinado a proteger la sociedad y a defender el honor de la nación ${ }^{69}$. El informe de la Oficina mereció un enérgico rechazo por parte de la Dirección de Intervención Civil, que consideraba que el nuevo régimen no sólo debía conllevar la sustitución de personas y de un matiz militar por otro civil, sino que la actuación debía fundamentarse en la aplicación de las bases del Protectorado. La crítica atacaba el fraudulento discur-

\footnotetext{
me el mes siguiente para dar «la sensación de la capacidad del elemento militar para el desempeño de la misión que le fue confiada». Véase AGA Caja M-1.275.

6s MAESTRE, Pedro: Divulgación y orientación del problema de Marruecos. Intervención Civil, Intervención Militar, op. cit., p. 285.

66 García Figueras, Tomás: «Las oficinas de Intervención Militar» en Anuario-Guía Oficial de Marruecos. Zona española. Zona Internacional. Posesiones españolas en el Norte de África. Gibraltar, op. cit., p. 264.

67 García Figueras, Tomás: Temas de Protectorado, Tetuán, Imprenta de Tropas Coloniales, 1926, p. 106

${ }^{68}$ AGA Caja M- 1.251.

69 BusQueTs, Julio: El militar de carrera en España, Barcelona, Ariel, 1971, $2^{\mathrm{a}}$ ed., 289 p.
} 
so que habían utilizado estos militares, pues acusaba directamente a los interventores militares de no actuar conforme a aquellos principios ${ }^{70}$.

La dualidad intervención militar / intervención civil también se había producido en la Zona francesa pero, por el contrario y desde el primer momento, Lyautey puntualizó los principios que debían regir la intervención, fuese ejercida por civiles o por militares. En una directiva de 1917, aclaró que «el reparto de las circunscripciones entre agentes civiles y agentes militares no se fundamenta sobre una diferencia de método sino sobre modalidades regionales». Las funciones interventoras fueron encomendadas a oficiales militares en las regiones en las que la situación política exigía la concentración de la acción administrativa y la fuerza militar y donde, incluso sin el empleo de la fuerza, el carácter de los marroquíes les llevaba a doblegarse más fácilmente ante la autoridad militar que ante cualquier otra. Junto a este sencillo planteamiento, Lyautey mostró una gran agudeza y flexibilidad al explicar que esta distribución no podía establecerse siguiendo criterios absolutos, pues por encima del mismo se encontraban las características personales: un militar "curtido en asuntos administrativos, libre de toda deformación profesional» - la cursiva es nuestra- podía, en provecho del interés general ejercer la intervención en una circunscripción con agentes civiles a sus órdenes, y un civil «con experiencia especial entre los indígenas y de Marruecos, [y con] una autoridad contrastada» podía dirigir una circunscripción con oficiales a sus órdenes ${ }^{71}$.

Los intentos «civilistas» del Real Decreto 16-9-1922 desaparecieron totalmente durante el Directorio de Primo de Rivera. La nueva Administración española decidió llevar a cabo el sometimiento de la Zona con predomino de la acción militar sobre la civil, como hemos comentado. Este planteamiento y la agudización de la situación bélica provocaron que en la Exposición del Real Decreto 11-5-1924 se señalara que la organización de la intervención propuesta en el Real Decreto 16-9-1922 no era la adecuada con la situación política existente en la Zona, "que impidió y sigue impidiendo la aplicación inmediata de la mayoría de sus preceptos». El nuevo Real Decreto otorgó un mayor protagonismo a la acción militar colocando la intervención militar bajo las órdenes del jefe del E.M. General del Ejército de operaciones, aunque mantuvo la civil, bajo dependencia de la Secretaría General, sobre el Majzen y las autoridades marroquíes de las ciudades y de las regiones «pacificadas».

Por otra parte, el artículo $3^{\circ}$ encomendó al alto comisario la obligación de indicar al Gobierno las circunscripciones preparadas para establecer un régimen preferentemente civil ${ }^{72}$. Sin embargo, el espíritu militar que impregnaba

\footnotetext{
${ }^{70}$ AGA Caja M-1.478.

71 GRUNER, Roger: Du Maroc traditionnel au Maroc moderne. Le contrôle civil au maroc. 19121956, op. cit., pp. 214-215.

$72 \mathrm{El}$ alto comisario, teniente general Luis Aizpuru Mondéjar, puso en marcha un proceso consultivo y, por ejemplo, en octubre de 1924, la Intervención militar de la Región Oriental informó que en Guelaya, Quebdana y Ulad Settut podía implantarse el régimen civil, mientras que en Beni
} 
la Exposición del Real Decreto, que se contradecía con lo dispuesto en este artículo, y el agravamiento de la situación militar provocaron una reducción los límites de la intervención civil. El año siguiente, el Real Decreto 20-5-1925 redujo la intervención civil al Majzen y a las autoridades de las ciudades. La decisión suponía la «consagración legal de la práctica [primorriverista] que siempre fue contrariai a asignar atribuciones interventoras a los civiles ${ }^{73}$. La subordinación de la intervención civil a la militar aún quedó más acentuada al adscribir al delegado de la Sección Civil de Intervención de Melilla a la Oficina Central de Intervención Militar de aquella región.

La dominación de numerosas cabilas tras el desembarco de Annual y en 1926 facilitó que las autoridades españolas se plantearan activar más decididamente el régimen de protectorado, pero la ideología del Directorio conllevó que en el ámbito rural todos los elementos interventores formaran parte y dependieran de una estructura militar; situación que se prolongó a lo largo de todo este periodo.

A medida que se iba vislumbrando el final del conflicto armado llegaron a plantear la posibilidad de ampliar el radio de acción de la intervención civil a las cabilas más pacificadas ${ }^{74}$. Incluso el alto comisario, teniente general José Sanjurjo Sacanell, efectuó unas declaraciones defendiendo la labor de los interventores civiles:

«la labor del interventor ha de ser de administración, perdiendo su carácter militar, y ahí aparece la labor del interventor civil, enterado, por su carrera, profesión o inclinaciones, de los estudios administrativos, y que pueda dedicarse de pleno a ellos»75.

Sin embargo, apenas tomaron medidas para ampliar el radio de acción de la intervención ejercida por civiles más allá de las ciudades.

La potenciación de la intervención civil no se produjo hasta el advenimiento de la República. Este fue uno de los criterios que guiaron la acción republicana en el Protectorado ${ }^{76}$. Tras la publicación del Decreto 3-6-1931 —que fue la primera disposición oficial encaminada a «des-militarizar» la Zona y que estableció una reducción de los efectivos, de los servicios y de las circunscripciones milita-

Said, Metalsa, Beni Buiahi y Tafersit podía atenuarse el régimen militar, dada su situación política y militar, e implantar progresivamente el civil. Véase AGA Caja M-1.442.

${ }^{3}$ LÓPEZ OLIVÁN, J.: Legislación vigente en la Zona de Protectorado español en Marruecos, Madrid, Gráficas Marinas, vol. 2, p. 90 nota 1.

${ }^{74}$ Real Orden Circular 29-7-1926.

75 REDACCIÓN: «El Marruecos de hoy y el de mañana. Interesantes manifestaciones del general Sanjurjo» en Revista Hispano-Africana (Madrid) 32 y 33 (1927), pp. 1-3/3.

76 MORAles Lezcano, Víctor: España y el Mundo Árabe: imágenes cruzadas, Madrid, Agencia Española de Cooperación Internacional \& Ministerio de Asuntos Exteriores, 1993, p. 25.

Hispania, LXV/2, núm. 220 (2005) 683-716 
res- ${ }^{77}$, la primera mención expresa para otorgar un carácter civil a las intervenciones se materializó en el Decreto 16-6-1931. En un artículo adicional, encomendó al alto comisario la proposición de nuevas normas para ejercer la acción interventora. Teniendo en cuenta la simplificación, la economía presupuestaria y la supresión de todo aquello que no fuera indispensable, debía proponer el establecimiento de "un régimen civil en los territorios pacificados» y la instauración o reorganización del régimen militar bajo el que debían de quedar sometidos los restantes territorios por razones de orden político o de seguridad.

La decisión de extender progresivamente el régimen civil en la Zona levantó airadas reacciones en los ambientes militares que incrementaron las tensiones con las autoridades republicanas. Muestra de la tirantez existente fueron, en noviembre de 1931, la destitución del delegado de Asuntos Indígenas, coronel Fernando Capaz - ante su resistencia a la reducción de las intervenciones militares_-78, y el informe que el general Miguel Cabanellas - jefe superior de las Fuerzas Militares en Marruecos-, presentó al Gobierno; en el que rechazaba cualquier tipo de crítica sobre la actuación de las intervenciones militares y defendía de forma absolutamente desproporcionada la labor que habían realizado, gracias «exclusiva y personalmente al entusiasmo y celo de los oficiales interventores». Las opiniones de Cabanellas reflejaban las ideas expuestas por otros militares a principios de los años veinte: ensalzamiento de la aptitud y de la actitud de los oficiales militares para el desempeño de la labor interventora y descalificación del personal civil.

Cabanellas no contemplaba de buen grado la posible exclusión de los militares de la intervención, para cuyo ejercicio consideraba idóneas las virtudes castrenses:

«Para el cargo de interventor se necesitan cualidades sobresalientes: abnegación y duro espíritu de trabajo; actividad juvenil precisa a quien ha de pasar muchas horas y muchos días a caballo; independencia de posición, si cabe holgura; gran responsabilidad atribuida a una gran solvencia personal y moral inestimable; inteligencia, hábito en el trato a indígenas, conocimientos de sus usos, costumbres, leyes, derecho e idioma, y sobre todo un desprendido amor por las cosas y la vida de Marruecos. Cualidades tan notables no son exclusivas de los oficiales del servicio; pero en muchos de ellos se cumplen y en todos ellos se aquilatan por cuanto a entusiasmo, sacrificio y responsabilidad y solvencia moral, toda vez que la disciplina militar y el no desligarse de su carrera, en la que son depuradamente seleccionados, son prenda y garantía pocas veces fallida al elegir».

77 Esta disposición se enmarcaba en el conjunto de reformas militares promovidas por Manuel Azaña, ministro de la Guerra. A modo de ejemplo, citamos los Decretos 25-4-1931, 8-5-1931, 2-61931 y 26-7-1931. Sobre la repercusión de estas reformas en el Ejército de África véase MORALES LEZCANO, Víctor: «L'Exèrcit d'África i les reformes militars: 1931-1936» en L'Avenç (Barcelona) 28 (1980), pp. 41-46.

78 MADARIAGA, María Rosa de: Los moros que trajo Franco... La intervención de tropas coloniales en la Guerra Civil, Barcelona, Martínez Roca, 2002, pp. 154-160.

Hispania, LXV/2, núm. 220 (2005) 683-716 
Paralelamente arremetía contra el conjunto del personal civil destinado a la Zona. En su opinión, los interventores civiles vivían en las ciudades «con despego hacia el campo y absoluto desinterés para las tribus e indígenas cabileños» y los servicios técnicos — «que han sesteado muellemente en Tetuán»- apenas habían hecho nada. Sin embargo, eludía comentar que los primeros tenían limitada su labor a los núcleos urbanos principalmente y los segundos realizaban su actividad en coordinación con las intervenciones militares - que consideraban el medio rural como un ámbito privado- y con los exiguos presupuestos que la Administración española ponía a su disposición. Cabanellas concluía su informe aconsejando la implantación de la intervención civil en diez cabilas exclusivamente: las cinco de Guelaya, Quebdana, Ulad Settut, Garbía, Sahel y El Hauz.

El informe mereció una réplica inmediata del alto comisario, López Ferrer, aunque ésta traslucía la timidez con que los gobiernos republicanos abordaron la reforma del Protectorado, en general, y de las intervenciones, en particular. López Ferrer defendía el establecimiento de un régimen civil en concordancia con el existente en España y porque hacía cuatro años que reinaba la paz en la Zona. Sin embargo, el alto comisario no parecía absolutamente convencido de este segundo argumento y su propuesta de implantar el régimen civil solamente se ampliaba a cuatro cabilas más de las citadas por Cabanellas: Beni Buiahi, Metalsa, Beni Aros y Beni Said. Además, admitía que existieran intervenciones civiles dirigidas por militares. Esta postura puede interpretarse como una concesión a quienes habían controlado de manera casi absoluta la intervención hasta el momento, como una estrategia para asegurar la continuidad de la misma - pues no había suficiente personal civil con experiencia en tales funciones- o como una manifestación más de la poco decidida política colonial republicana. A la vista de las posteriores resoluciones republicanas, y teniendo en cuenta que López Ferrer no mencionó el posible carácter transitorio de la intervención militar, creemos que los tres aspectos influyeron en ella ${ }^{79}$.

La primera disposición oficial metropolitana que concretó la implantación de la intervención civil en las cabilas fue el Decreto 29-12-1931, que ha sido considerado «la clave de bóveda de las reformas administrativa y política del Protectorado bajo la II República» ${ }^{80}$. El Decreto intentó organizar una estructura que permitiese al alto comisario civil implantar y desarrollar con normalidad el régimen de protectorado y, entre las novedades que presentaba merece destacarse la nueva organización política de la Zona, que quedó dividida en regiones civiles y militares, paso previo para implantar progresivamente el régimen civil y potenciar la figura de los interventores. A pesar de que el Decreto subrayaba la mayor importancia que debía tener la acción política bajo inspira-

79 El informe de Cabanellas y la réplica de López Ferrer fueron publicados por el diario El Sol los días 13 y 14 de noviembre de 1931, respectivamente.

80 MORAles LezCANO, Víctor: «El protectorado español en Marruecos bajo la II República (las reformas administrativas)" en Actas de las Jornadas de Cultura Árabe e Islámica. 1978, Madrid, Instituto Hispano-Árabe de Cultura, pp.457-489/464 nota 19.

Hispania, LXV/2, núm. 220 (2005) 683-716 
ción civil, la intervención civil se implantó solamente en veintitrés cabilas y en el resto subsistió la militar ${ }^{81}$. Con objeto de que el alto comisario pudiera organizar y unificar la acción interventora, la disposición la colocó bajo su dependencia directa. Aunque subrayaba el principio de que la intervención estuviese guiada por criterios únicos, mantuvo la dualidad de su gestión inmediata.

$\mathrm{La}$ aplicación del Decreto no estuvo libre de dificultades y tensiones, pero no sólo por la actitud de los militares, sino también a consecuencia del desbarajuste administrativo existente. A principios de marzo de 1932, la Inspección de Intervenciones Militares advirtió que habían surgido problemas al pasar determinadas regiones al régimen civil. Estos problemas eran debidos a que el personal militar desplazado no tenía acoplamiento en las nuevas plantillas, a los numerosos retrasos existentes en el pago de los haberes y a que el cese de los interventores militares no fue acompañado automáticamente del nombramiento de los civiles. Este última circunstancia perjudicaba enormemente la continuidad de la acción interventora, pues los cesados no podían permanecer más tiempo en el puesto ${ }^{82}$. De todas formas, tampoco se pueden magnificar las perturbaciones administrativas que se produjeron en el traspaso de las cabilas al régimen civil. En marzo de 1932, la Oficina Central de Intervenciones y Tropas Jalifianas de Tetuán informó que El Hauz, Uadrás y Beni Hozmar habían pasado al régimen civil «con toda normalidad» y que la medida había sido bien acogida por los indígenas ${ }^{83}$.

La implantación de las intervenciones civiles en el campo originó una nueva situación sobre la que la superioridad no había dictado disposiciones reglamentarias. Para cubrir este vacío, en mayo de 1932, el alto comisario, López Ferrer, encargó la redacción de un proyecto de reglamento sobre el régimen interior de las intervenciones civiles a una comisión formada por representantes de la Inspección de Intervenciones y Tropas Jalifianas y funcionarios civiles del Protectorado ${ }^{84}$. Desconocemos si el Reglamento llegó a entrar en vigor, en todo caso la unificación de las intervenciones en 1934 debió comportar modificaciones, ya que los interventores militares desaparecieron como tales.

El Decreto 29-12-1931 supuso un primer paso para extender definitivamente la intervención civil a las cabilas, pero el establecimiento de un sistema interventor único se retrasó hasta 1934. La existencia de un doble sistema in-

${ }^{81}$ Las Intervenciones civiles no llegaban a extender sus atribuciones ni al $40 \%$ del territorio ni de la población. Véase INSPECCIÓN DE INTERVENCión Y FuERZAS JALIFIANAS: Vademécum. Año 1931, Ceuta, Imprenta «África», s.a. [1932], pp. 69-70. Un mapa acerca de las cabilas que el Decreto 29-12-1931 colocó bajo Intervención Civil y Militar se encuentra en VILlanOVA, José Luis: «La constante mutación de la organización político-administrativa del Protectorado español en Marruecos» en Nogué, Joan y Villanova, José Luis (eds.): España en Marruecos (1912-1956). Discursos geográficos e intervención territorial, Lleida, Milenio, 1999, pp. 435-465/454.

82 AGA Caja M-1.251.

83 AGA Caja M-1.256.

${ }^{84}$ AGA Caja M-3.184. 
terventor -e incluso triple si tenemos presente la acción ejercida por los cónsules en las ciudades-, en el que militares y civiles se repartían el ejercicio de la labor interventora, no tenía demasiado sentido una vez que la Zona había sido pacificada hacía más de seis años - al menos oficialmente- y habiéndose establecido en la metrópoli un régimen de carácter "civilista»" ${ }^{85}$. Sin embargo, los problemas internos a los que debían hacer frente los Gobiernos republicanos, la ausencia de una clara política colonial, las resistencias que oponían los sectores africanistas vinculados a los militares y la obstinación de éstos para evitar perder el control efectivo de la política en la Zona dificultaron la implantación de un sistema único.

El Decreto 26-6-1934 procedió a la fusión de las intervenciones militares y civiles en un nuevo Servicio de Intervenciones ${ }^{86}$, adscrito a la Delegación de Asuntos Indígenas, que asumió la intervención en las ciudades y en las cabilas ${ }^{87}$.

A partir del año siguiente el régimen político fue idéntico en todas las cabilas ${ }^{88}$, pero la fusión de las intervenciones no comportó la instauración de un sistema estrictamente civil, pues en los nombramientos de interventores en igualdad de condiciones se daba preferencia para ocupar destino en las oficinas del campo a los militares que hubieran ejercido funciones interventoras o prestado servicios en las Fuerzas Indígenas ${ }^{89}$. Por otra parte, la necesidad de no desmantelar completamente el sistema existente motivó que el Decreto 21-111934 dispusiera el acoplamiento en el nuevo Servicio del personal que formaba parte de las intervenciones el treinta de junio. De este modo, se integraron en la nueva estructura 198 interventores, militares en su mayor parte ${ }^{90}$. Este hecho tendría nefastas consecuencias para el régimen republicano en $1936^{91}$.

85 Sobre las consecuencias, en el Protectorado, de las reformas militares llevadas a cabo por los gobiernos republicanos, véase MORALES LEZCANO, Víctor: «L'Exèrcit d'Àfrica i les reformes militars: 1931-1936» en L'Avenç (Barcelona) 28 (1980), pp. 41-46.

${ }^{86}$ La primera propuesta para crear un «Servicio de intervención» único con personal civil o militar, que hemos localizado, fue realizada por la Comandancia General de Melilla en noviembre de 1922, en el marco de la reformas propuestas en el Real Decreto 16-9-1922. Véase AGA Caja M-1.251. Pero diferentes circunstancias impidieron avanzar en esta dirección, como ya hemos comentado.

87 Por otra parte, fusionadas las intervenciones, no era consecuente que los cónsules continuaran ejerciendo la labor interventora en las ciudades. El Decreto 14-11-1934 estableció que los cónsules destinados en la Zona sólo desarrollarían las funciones propias de su cargo.

${ }^{88}$ El Decreto 15-2-1935, que reorganizó los servicios de la Alta Comisaría, eliminó definitivamente la distinción entre regiones civiles y militares.

89 Véase Decreto 18-12-1933.

90 La «Relación del personal del Servicio de Intervenciones que queda definitivamente clasificado en las categorías que se expresan en virtud del D 21-11-34 y de las normas para su aplicación» se encuentra en Boletín Oficial de la Zona de Protectorado de España en Marriecos, 1935, vol. 1, pp. 600-606.

${ }^{91}$ El papel de la mayoría de los interventores fue determinante en el éxito de la movilización de marroquíes para combatir en las filas franquistas. Sobre este asunto, véanse: FLEMING, E.: «Spanish Morocco and the Alzamiento nacional, 1936-1939. The Military, Economic and Political Mobilization of the Protectorate» en Journal of Contemporary History (London) 18 (1983), pp. 27-42; BENEjelloun, Abdelmajid: «Reévaluation des causes de l'enrolement de marocains dans les rangs

Hispania, LXV/2, núm. 220 (2005) 683-716 
A pesar de las facilidades que las reformas ofrecían a los militares para continuar en las intervenciones, éstos reaccionaron con acritud y volvieron a manifestar su profundo rechazo a que los civiles pudiesen acceder a todos los ámbitos interventores al considerar que no estaban preparados. García Figueras manifestó que la complejidad de la tarea, precisaba

«tantos matices y tal suma de virtudes que la conclusión fructífera no puede ser más que ésta: La función interventora debe ser ejercida por los aptos para ello, por los que con un sentimiento exaltado del patriotismo, tengan una sólida formación de todo orden, un concepto diáfano de los deberes y responsabilidades del mando, sean del campo que sean, provengan de donde provengan» $\$ 2$.

Aunque aparentemente pueda pensarse que defendía el nuevo sistema y que apelaba exclusivamente a la exigencia de que el personal estuviese capacitado, en realidad realizaba una apología de las supuestas virtudes castrenses. Buena muestra de ello es el texto en el que calificó a la mayor parte de los interventores civiles de «fracasados o ambiciosos» que carecían de la preparación previa necesaria. Para García Figueras esta preparación sólo la poseían los interventores militares tras su paso por las Academias militares ${ }^{93}$. El nombramiento de interventores civiles también fue criticado por el general Emilio Mola, quien lo consideró «un desastre» y los acusó de ser «desconocedores en absoluto de los asuntos marroquíes» y de creer «cumplir con su deber apareciendo por la cabila los días de zoco, y otros ni eso" ${ }^{94}$.

El ascenso al poder de los militares a raíz de la insurrección de 1936 no modificó oficialmente la estructura interventora levantada en el periodo republicano. Sin embargo, las autoridades franquistas la impregnaron de un cariz predominantemente militar —en consonancia con las características del régimen-y las in-

franquistes, 1936-39, sous l'angle exclusif du Maroc» en Revue Maroc-Europe (Rabat) 7 (1994), pp. 219-234 y "La participation des rifains à la guèrre civile espagnole» en Revue d'Histoire Maghrébine (Zaghouan), 87-88 (1997), pp. 459-461; BERGES, Patrick: «D'une guerre a l'autre: le «Maroc espagnol» dans la tourmente. (17 juillet 1936 - septembre 1940)» en Revue Maroc-Europe (Rabat) 1 (1991), pp. 107-133; MADARIAGa, María Rosa de: «The Intervention of Moroccan Troops in the Spanish Civil War» en European History Quarterly (London) 22 (1992), pp. 67-97 y Los moros que trajo Franco... La intervención de tropas coloniales en la Guerra Civil, op. cit., pp. 153-173; BALFOUR, Sebastian: Abrazo mortal. De la guerra colonial a la Guerra Civil en España y Marruecos (1909-1939), op. cit., pp. 493-516; El MERRoun, Mustapha: Las tropas marroquies en la Guerra Civil española. 1936-1939, Madrid, Almena, 2003, pp. 7-69 y las aportaciones recogidas en GonZÁlEZ ALCANTUD, José Antonio (ed.): Marroquíes en la guerra civil española. Campos equívocos, Rubí (Barcelona), Anthropos, 2003, $231 \mathrm{p}$.

92 García Figueras, Tomás: «Hacia un Protectorado eficiente. La vocación del Interventor», África (Ceuta) marzo (1934), pp. 59-60/59.

${ }_{93}$ García Figueras, Tomás: Marruecos. (La acción de España en el Norte de África), Madrid, Ediciones Fé, 1939, p. 251.

94 Mola, Emilio: Obras completas, Valladolid, Librería Santarén, 1940, p. 1.112. 
tervenciones pasaron a constituir un coto casi exclusivo de los militares: los puestos superiores del Servicio fueron ocupados por militares, el número de interventores civiles se redujo notablemente - posiblemente la mayor parte de los depurados en 1936 fueran civiles fieles a los principios republicanos-9s y durante la Guerra Civil ingresaron en el Servicio oficiales «provisionales»"96.

Por otra parte, se restringió la entrada de aspirantes civiles en la Academia de Interventores, creada en 194797: en la segunda, tercera y cuarta convocatorias para ingresar en ella tuvieron preferencia los jefes y oficiales de complemento y en la octava convocatoria se exigió la condición de soltería sólo a los aspirantes civiles. Junto a estas restricciones, diversos miembros del Ejército que ocupaban cargos de responsabilidad en la Administración del Protectorado, manifestaron su rechazo a la entrada de civiles en la Academia. A modo de ejemplo, podemos señalar que, ante la organización del séptimo curso, la Dirección de la Academia propuso a la Delegación de Asuntos Indígenas no admitir - salvo casos excepcionales - a personal civil. La petición argumentaba que los civiles no estaban acostumbrados a aquel tipo de vida; circunstancia que provocaba comentarios muy críticos por parte de los marroquíes. El mismo año, las Intervenciones Territoriales de Chauen y del Lucus criticaron la «excesiva» asistencia de personal civil a los cursos de la Academia ${ }^{98}$. Las decisiones adoptadas y las presiones existentes provocaron que el porcentaje de alumnos civiles que pasaron por el centro solamente fuera algo más del $20 \% 99$. Sin embargo, este pequeño porcentaje aún puede relativizarse más si consideramos que el «espíritu militar» no debía de ser del todo ajeno a muchos de alumnos civiles: varios eran hijos de antiguos interventores y los dos civiles del tercer curso tenían acreditada «su vocación de milicia» al haber realizado milicias universitarias. Seguramente, esta información constaría en las instancias de solicitud de ingreso y la Alta Comisaría debió valorarla positivamente ${ }^{100}$.

${ }_{95}$ El 21 de julio se constituyó en Tetuán una comisión que, en cinco meses, destituyó a cuarenta y seis interventores. Véase IBN AzzUZ HAKIM, Mohammad: Actitud de los moros ante el Alzamiento. Marruecos 1936, Málaga, Algazara, 1997, pp. 139-140.

96 El Dahir 4-5-1937 creó la categoría de interventores adjuntos provisionales, cargos que serían ocupados por alféreces provisionales.

97 Este centro de formación para los aspirantes a interventor fue creado por la Orden 24-121946. Sobre el mismo véase VILlANOVA, José Luiș: La organización política, administrativa y territorial del Protectorado de España en Marruecos (1912-1956). El papel de la Intervenciones, op. cit., vol. 2., pp. 580-599.

98 AGA Caja M-3.964.

99 Villanova, José Luis: «La formación de los interventores en el Protectorado español en Marruecos (1912-1956)» en RodríGUeZ Mediano, Fernando y Felipe, Helena de (eds.): El Protectorado español en Marruecos. Gestión colonial e identidades, Madrid, Consejo Superior de Investigaciones Científicas, 2002, pp. 247-280/267.

100 ET-TAByi (pseud. de Maldonado VÁzQuez, Eduardo): «Visita de la Academia de Interventores a la Región del Kert» en Marruecos. Exponente Gráfico e Informativo de la acción protectora de España (Tetuán) 17-18 (1950), p.s.n.

Hispania, LXV/2, núm. 220 (2005) 683-716 
Durante esta última etapa del Protectorado también continuó insistiéndose en las mayores cualidades que reunían los militares para ejercer la Intervención y en la menor capacidad de sacrificio de los civiles ${ }^{101}$. Estas opiniones, en la línea de las expuestas anteriormente, generaron la creación de una extendida corriente de menosprecio por parte de los interventores procedentes de la milicia hacia aquellos que venían del ámbito civil ${ }^{102}$.

No podemos finalizar este artículo sin mencionar que las tensiones entre el personal civil y militar también se reprodujeron en la Zona francesa ${ }^{103}$, aunque posiblemente fueron menos agudas. En 1920, Lyautey denunció la falta de comunicación y de confianza entre ambos grupos, pero la analogía de sus funciones, el paso conjunto por un curso de formación en Rabat, la pertenencia a una única dirección central y sus mismas preocupaciones ante el ascenso del nacionalismo fueron elementos que contribuyeron a amortiguar - sin eliminar completamente- estos problemas ${ }^{104}$. De todas maneras, los contrôleurs civils consideraron que no estaban suficientemente asociados a la política desarrollada y que su experiencia no era aprovechada al máximo ${ }^{105}$.

\section{CONCLUSIÓN}

La función interventora constituyó el fundamento sobre el que se desarrolló el Protectorado español en Marruecos. Su importancia no sólo radicaba en la facultad de fiscalización de la actuación de las autoridades indígenas, sino también en las múltiples atribuciones de que dispusieron los interventores en virtud del convenio hispano-francés de 1912 que otorgaba a las autoridades españolas la facultad de introducir reformas administrativas, económicas, financieras, etc. en la Zona.

La inexperiencia española en la administración de territorios y sociedades bajo el régimen de protectorado, la ausencia de un armazón teórico consistente sobre cómo llevarla a cabo y la resistencia de la mayor parte de la población de la Zona a aceptar el sistema de protectorado dificultaron enormemente el desarrollo de la labor de los interventores, especialmente hasta 1927.

101 Respectivamente, MATERNE (teniente coronel): Los últimos consejos, Ceuta, Imp. Imperio, 1941, 19 p. y BLANCO IZAGA, Emilio: La técnica en servicio exterior de Estado, s.l. [Tánger], Editorial Tánger, $1941,70 \mathrm{p}$.

102 Véase MATEO Dieste, Josep Lluís: La «bermandad» bispano-marroquí. Política y religión bajo el Protectorado español en Marruecos (1912-1956), op. cit., pp. 79-101.

${ }_{103}$ BEN MLIH, Abdellah: Structures politiques du Maroc colonial, Paris, L'Harmattan, 1990, pp. 267-270.

${ }^{104}$ GRUNER, Roger: Du Maroc traditionnel au Maroc moderne. Le contrôle civil au Maroc. $1912-$ 1956 , op. cit., 254 p.

105 BRUNO, Henry: En Busca de una Política Indígena, texto mecanografiado localizable en la Biblioteca Nacional, fondo "África», Caja 7.004-15. Este texto es una traducción de un artículo publicado en el número 8 del Bulletin de l'Afrique Française, correspondiente al mes de agosto de 1933.

Hispania, LXV/2, núm. 220 (2005) 683-716 
La aplicación del modelo de administración indirecta en el Protectorado mediante la fórmula de la intervención de las autoridades indígenas por parte de las españolas no se implantó realmente hasta la total dominación de la Zona. Hasta 1927 solamente funcionó el sistema de intervenciones en el Majzen central y en las ciudades, donde las autoridades eran intervenidas por la Alta Comisaría, directamente, y por los cónsules, respectivamente. A pesar de algunos tímidos intentos por extender la intervención al campo, los oficiales de la Policía Indígena y los interventores militares ejercieron generalmente el gobierno directo.

Por otro lado, la escasa elaboración teórica de la política colonial española motivó que durante años numerosas autoridades confundieran «intervención civil» con «régimen de protectorado» e «intervención militar» con «administración directa», en clara contradicción con el régimen que establecía el convenio de 1912. Además, la resistencia de la mayor parte de la población marroquí frente la penetración armada española, el rechazo a reconocer a las nuevas autoridades jalifianas y las reticencias de gran parte de los militares - quienes dada la situación bélica de la Zona gozaban de una gran preeminencia- a establecer un modelo que chocaba con su ideología castrense sirvieron de excusas para retrasar su implantación.

A partir de 1927, y a pesar de que las autoridades españolas insistieron continuamente en la necesidad de ejercer la intervención correctamente con objeto de respetar —al menos teórica y formalmente - el sistema establecido en el convenio de 1912, en numerosas ocasiones los interventores tomaron decisiones sin tener competencias para ello o se entrometieron en la gestión de las autoridades marroquíes más allá de lo que era preceptivo. No obstante, en la Zona española parece ser que las autoridades marroquíes gozaron de mayor autonomía que en la francesa; aunque no puede olvidarse que la misma se permitió únicamente en los casos en que no chocaba con los planteamientos y los intereses de las autoridades coloniales.

A lo largo del Protectorado se enfrentaron dos enfoques opuestos sobre quienes debían ejercer la intervención, militares o civiles, que reflejaban la pugna de ambos grupos por controlar la gestión del Protectorado y dos maneras de entenderla.

El triunfo de los planteamientos militaristas en la penetración española ante la resistencia de las cabilas, la importante presencia de militares en la Zona desde los inicios del Protectorado y los planteamientos ideológicos de los regímenes políticos de los generales Primo de Rivera y Franco motivaron que los militares gozasen de preeminencia sobre los civiles en el ejercicio de la intervención.

A pesar de los tímidos intentos realizados en la década de los años veinte, la intervención civil no se extendió definitivamente a las cabilas hasta el periodo republicano. Sin embargo, la falta de decisión de las autoridades para apartar a los militares de la intervención - que tendría nefastas consecuencias para la República en 1936 - y el carácter del régimen franquista, posteriormente, 
facilitaron que éstos continuaran ocupando la mayoría de los puestos. La mayor parte de los nombrados o confirmados tras la unificación de las intervenciones, en 1934, y de los admitidos en la Academia de Interventores, a partir de 1947, fueron jefes y oficiales del Ejército.

La pugna entre civiles y militares también sacó a la luz el desprecio con que los segundos - convencidos de su innata superioridad - observaron a todos los funcionarios civiles destinados a la Zona, y especialmente a los que desempenaban funciones interventoras. Los partidarios de que los militares monopolizasen la intervención, conscientes de que una vez asegurada la pacificación de la Zona no podía defenderse directamente el mantenimiento de una intervención militar e interesados en no perder el control sobre la actividad que constituía el fundamento del Protectorado, decidieron criticar abiertamente las aptitudes de los interventores civiles y descalificar la gestión que llevaban a cabo. Obsesionados por resaltar las virtudes castrenses y la idoneidad de los militares para ejercer la intervención olvidaron, conscientemente, mencionar los numerosos errores que oficiales de la Policía Indígena e interventores militares habían cometido y la falta de rigor en su trabajo. 